\title{
CHARACTERIZING THE EFFECT OF VIDEOPHONE CONVERSATIONS ON INTERSECTION DRIVING PERFORMANCE
}

\author{
John G. Gaspar ${ }^{1}$, Ronald Carbonari ${ }^{2}$, Henry Kaczmarski ${ }^{2}$, \& Arthur F. Kramer ${ }^{2}$ \\ ${ }^{1}$ National Advanced Driving Simulator, University of Iowa \\ Iowa City, Iowa, USA \\ ${ }^{2}$ Beckman Institute for Advanced Science and Technology, University of Illinois \\ Urbana, Illinois, USA \\ Email: john-gaspar@uiowa.edu
}

\begin{abstract}
Summary: The present study examined the efficacy of videophone conversations for enhancing conversation partner situational awareness and mitigating cell phone distraction during intersection drives. Younger and older drivers drove through simulated intersections in four conditions: undistracted, with an in-car passenger, with a remote partner who could see the driver and a subset of the driving scene via a videophone, and with a remote partner on a cell phone. Relative to the cell phone condition, passenger and videophone conversations enhanced situational awareness and mitigated distraction. Younger and older drivers showed similar benefits, although there were age-related costs to driving performance overall. Videophone information offers a simple and promising potential strategy to enhance partner situational awareness during cell phone conversations, even when the conversation partner can see only a subset of the driving scene.
\end{abstract}

\section{INTRODUCTION}

Cell phone conversations have a negative impact on driving performance in certain situations. Cell phone conversations slow drivers' response times to unexpected events (Horrey \& Wickens, 2006), reduce lateral vehicle control (Drews et al., 2008), and impair situational awareness (Ma $\&$ Kaber, 2005). Conversations impair driving performance when they divert a driver's limited attentional resources from the driving task. The result of divided attention is that drivers are more likely to miss critical events. Strayer and colleagues (2004), for example, found evidence of inattentional blindness when drivers conversed on a hands-free phone. McCarley and colleagues (2004) similarly found poorer change detection for driving scenes when observers were distracted.

Importantly, however, not all conversations have a similar effect on driving performance. Evidence suggests that conversing with an in-car passenger may be less disruptive than talking to a remote cell phone partner (at least for experienced adult drivers). Drews, Pasupathi, and Strayer (2008) compared the effects of cell phone and passenger conversations on performance in a simulated highway drive. Drivers conversing with an in-car passenger were less likely to miss a specified exit than were drivers who conversed with a remote partner via a cell phone (see also Charlton, 2009). Critically, this benefit appears to be driven by the fact that passengers can see the driver and driving environment and thus have enhanced situational awareness. Drews and colleagues (2008) found that, compared to cell phone partners, passengers were more likely to talk about traffic, modulated their conversations during demanding situations, and helped alert drivers to information (e.g., exit signs) in the driving scene. 
These results raise the question of whether cell phone distraction can be mitigated by simply making the remote conversation partner more aware of the driving situation. To test this hypothesis, Gaspar and colleagues (in press) provided remote conversation partners views of the driving scene via a videophone, consisting of two monitors showing live video of the driver and driving scene (Figure 1C). This condition was compared against a no distraction baseline, a passenger conversation, and a cell phone conversation, during a busy highway drive with unexpected critical events such as vehicles merging in front of the driver. Both passenger and videophone conversations reduced the likelihood of collisions relative to the cell phone condition (though, importantly, there was still a cost relative to distraction-free driving). The benefit of videophone conversations relative to cell phones appears to be driven by changes in situational awareness. Videophone partners were more likely to reference traffic and modulated their conversations, relative to the cell phone condition.

The goal of the present study was to determine whether there was a benefit for videophone conversations over cell phone conversations in different driving situations, particularly those where critical information occurs outside the view afforded by the videophone. This study compared the effects of videophone, passenger, and cell phone conversations against a nodistraction baseline during simulated intersection drives. Compared with the highway task from the previous study where videophone partners could see most of the critical information because it happened in front of the driver (Figure 2A), videophone partners in the intersection task were unable to see cars approaching from the left and right (Figure 2B) and thus had a much more restricted view than in-car passengers. We therefore hypothesized that the benefit of videophones relative to cell phones, in terms of situational awareness, might be reduced at intersections. A secondary goal of the project was to determine whether older adults could also benefit from videophones. Older adults show both physical and cognitive limitations that might prevent conversation partners from utilizing additional video information. However, older adults may also be able to utilize their extensive driving experience to overcome such limitations (e.g., Kramer et al., 2007).

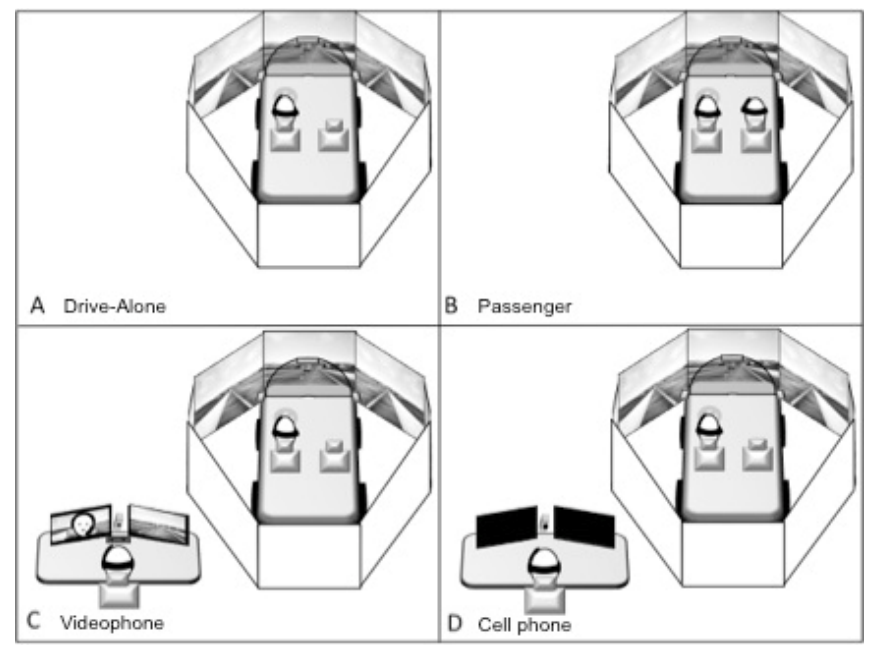

Figure 1. Conversation conditions from Gaspar et al. (in press) and the present study 

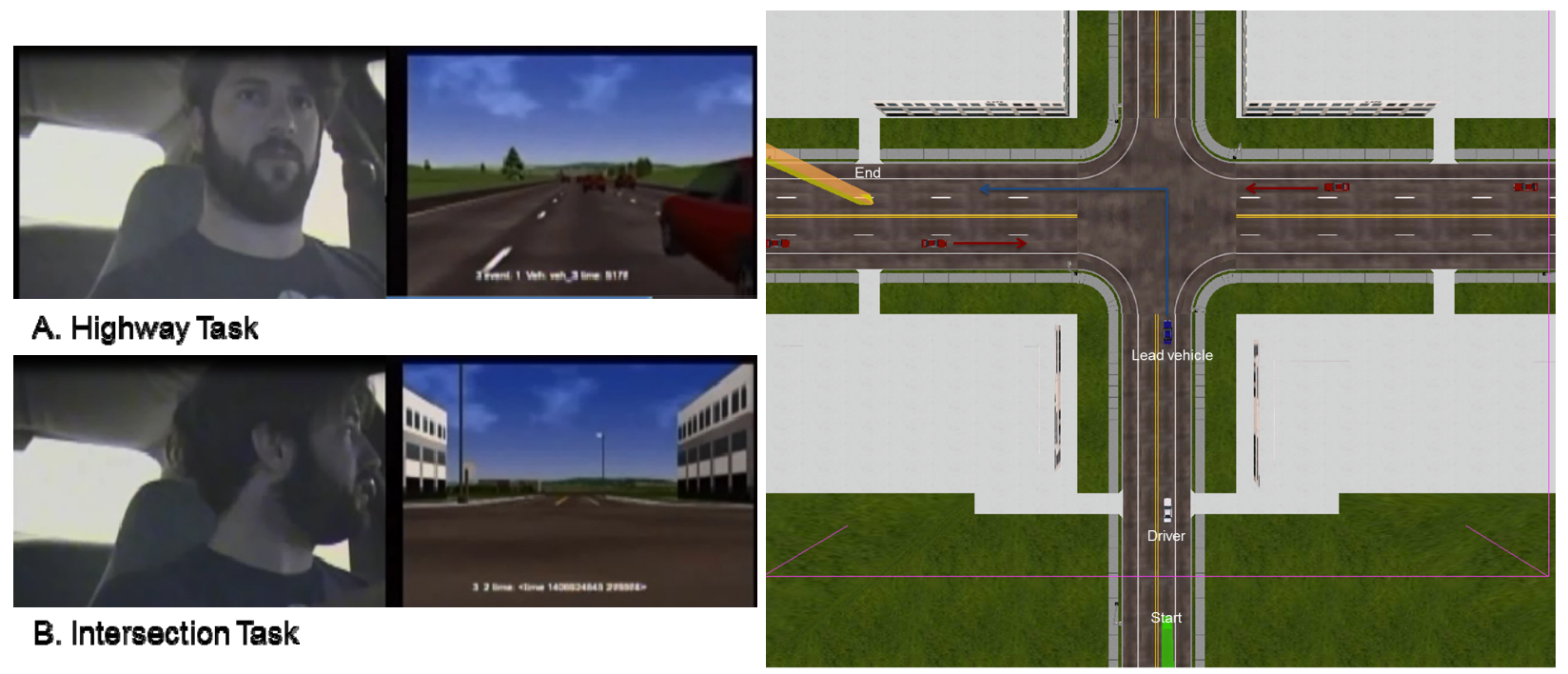

A. Highway Task

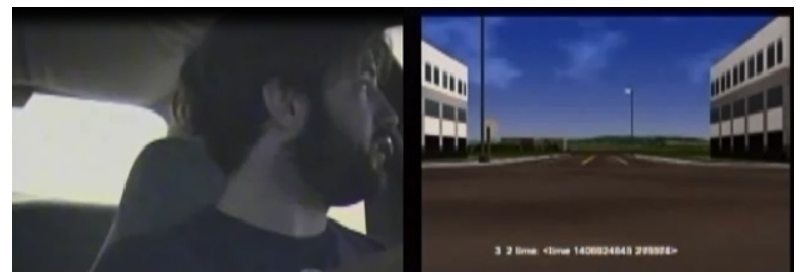

B. Intersection Task

Figure 2. Depiction of what videophone partners saw during the highway task (A) from Gaspar et al. (in press) vs. the intersection task (B) from the present study, and a diagram of a left turn scenario

\section{METHOD}

\section{Participants and Apparatus}

60 younger $($ mean age $=21.57, \mathrm{SD}=2.42)$ and 60 older $($ mean age $=67.28, \mathrm{SD}=4.73)$ adults who passed a screening drive were randomly paired (young/young, old/old). All participants were currently licensed active drivers free of medical conditions affecting driving. The Beckman Institute Illinois Simulator Lab driving simulator was used for data collection. The fixed-based DriveSafety simulator consists of a fully-instrumented Saturn surrounded by 8 projected screens, creating a 360 degree field of view. A SmartEye eye tracking system recorded driver head and eye movements.

\section{Driving Task}

The intersection task was based on scenarios developed by Romoser and Fisher (2009). Drivers drove through six discrete stop-controlled two-way intersections. The task comprised two left turns, two right turns, and one straight maneuver. Each drive began with the driver located behind a lead vehicle (LV), which executed a left or right turn or proceeded straight through the intersection. Drivers were instructed to approach the intersection slowly and to turn in the same direction as the LV, but were told they did not need to follow closely. Oncoming traffic was generated from the driver's left and right. Vehicles were generated $137 \mathrm{~m}$ from to the left and right of the center of the intersection at a random 5-10s interval. Figure 2 presents a diagram of one of the left turn scenarios. After the driver traversed the intersection, the screens dimmed and the driver was repositioned at the next intersection.

\section{Secondary Tasks and Procedure}

The experiment was a within-subjects design consisting of four blocks of conversation conditions. Upon entering the lab, one member of the pair was randomly assigned as the driver 
and the other member served as the conversation partner throughout the entire session. In 3 of the 4 blocks, pairs engaged in naturalistic conversations where they conversed freely about trips they had taken (Gaspar et al., in press). The order of the conversation conditions was counterbalanced across participants.

A. Drive-Alone. The driver drove without conversing.

B. Passenger Conversation. The driver drove while conversing with the conversation partner as an in-car passenger.

C. Videophone Conversation. The driver and conversation partner conversed remotely, as in the cell phone condition. However, this time the conversation partner could see live video of the driver and driving scene presented on two 19-inch displays. The driver feed was a live camera mounted unobtrusively on the car's dashboard. For the driving scene, the front of the 8 projected simulator images was duplicated and presented to the conversation partner (see Figure 2B). D. Cell Phone Conversation. The driver and conversation partner conversed remotely via a hands-free microphone and speaker. The conversation partner, located in a separate room, is unable to see the driver or the driving simulator.

\section{RESULTS}

\section{Situational Awareness}

The first goal of the study was to determine whether the videophone enhanced partner situational awareness relative to the cell phone. Conversations were coded by an independent rater and time-locked to the driving data. Situational awareness was defined by the frequency of partnerinitiated references to the immediate traffic scene (Drews et al., 2008). An increase in partnerinitiated traffic references indicates that partners were more attentive to the driving scene. As seen in Figure 3, there was a main effect of conversation condition on partner-initiated traffic references $\left(\mathrm{F}(2,58)=.4 .225, \mathrm{p}=.019, \eta^{2} \mathrm{p}=.140\right)$. Planned comparisons showed that partners made more traffic references in the passenger $(\mathrm{t}(29)=2.902, \mathrm{p}=.007)$ and videophone $(\mathrm{t}(29)=$ $2.420, \mathrm{p}=.023)$ conditions compared to the cell phone condition. Neither the main effect of age $\left(\mathrm{F}(2,58)=.113, \mathrm{p}=.893, \eta_{\mathrm{p}}^{2}=.004\right)$, nor the interaction between condition and age $(\mathrm{F}(2,58)=$ $\left..365, \mathrm{p}=.696, \eta^{2} \mathrm{p}=.014\right)$, were significant. Importantly, drivers also initiated more traffic references in the passenger and videophone conditions than the cell phone condition ( $\mathrm{p}$ 's $<.05)$.

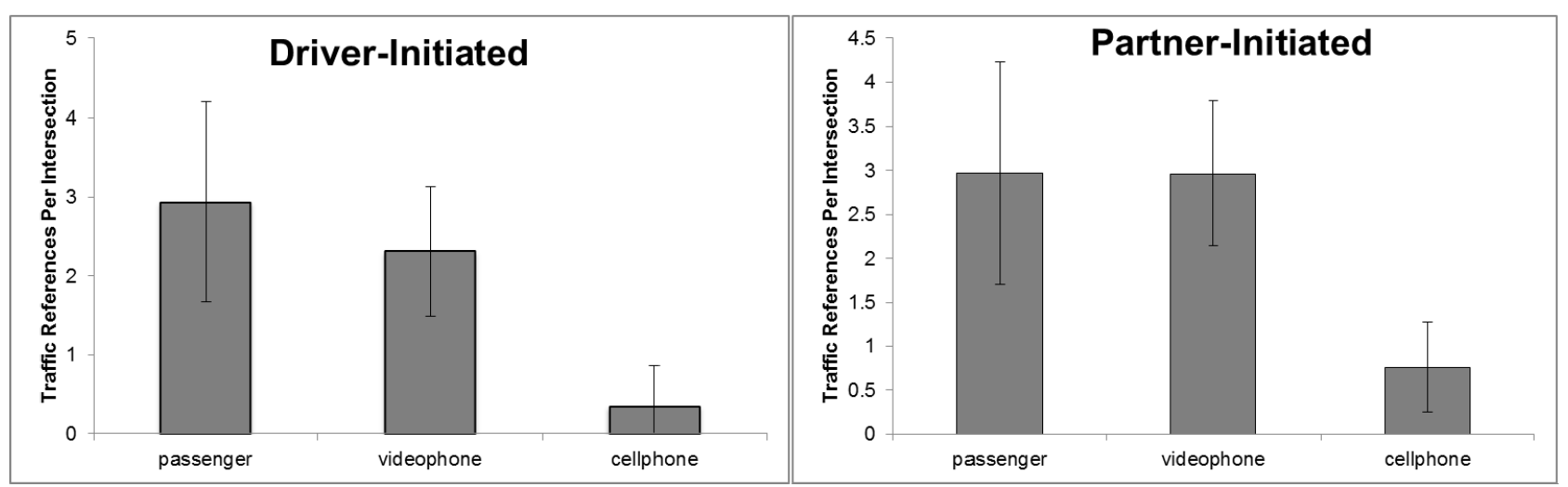

Figure 3. Driver- and partner-initiated traffic references per intersection. Error bars represent withinsubjects standard errors (Franz Loftus, 2012) 


\section{Driving Performance}

Our next goal was to characterize the effect of conversation condition on decision making and visual scanning relative to the no-distraction baseline condition.

Time to Initiate Turns (Figure 4). Time to initiate a turn was defined as the time from vehicle speed reaching 0 until the driver began accelerating. Average time to initiate a turn was used as an index of decision making, with longer times indicating slower, and possibly impaired, decisions. There was a main effect of conversation condition $\left(F(3,57)=5.885, p=.001, \eta^{2} p=\right.$ $.098)$, as well as a main effect of age, $\left(\mathrm{F}(3,57)=7.584, \mathrm{p}<.001, \eta_{\mathrm{p}}^{2}=.123\right)$, on turn initiation time. Planned comparisons showed that drivers waited longer in the cell phone condition compared to both the passenger $(\mathrm{t}(29)=2.123, \mathrm{p}=.042)$ and videophone $(\mathrm{t}(29)=2.855, \mathrm{p}=.008)$ conditions. As expected, younger drivers initiated turns significantly faster than older drivers, $\left(\mathrm{F}(3,57)=7.584, \mathrm{p}<.001, \eta_{\mathrm{p}}^{2}=.123\right)$, but the interaction between condition and age was not significant $(\mathrm{p}>.10)$.

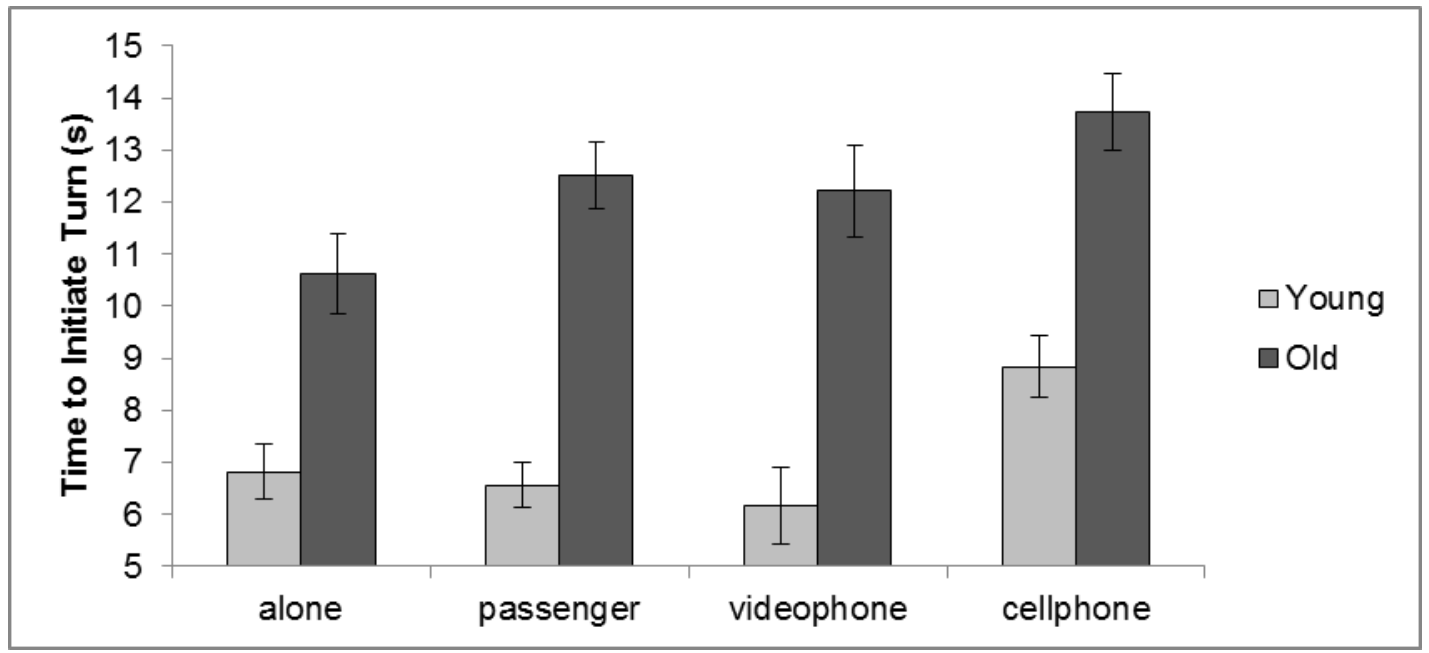

Figure 4. Average time to initiate a turn at intersections. Error bars represent within-subjects standard errors (Franz \& Loftus, 2012)

Secondary Glances (Figure 5). We also examined drivers' visual behavior upon initiating a turn by comparing the number of trials were drivers made a secondary glance, defined as a glance in the opposite direction of the turn after the driver began accelerating from a stopped position (Romoser \& Fisher, 2009). Previous research shows that older adults make fewer secondary glances than younger drivers, and a lack of secondary glances is theorized to contribute to crash risk at intersections (Romoser \& Fisher, 2009). As predicted, older drivers made fewer secondary glances than younger drivers $\left(\mathrm{F}(3,57)=4.542, \mathrm{p}=.006, \eta^{2} \mathrm{p}=.080\right)$. However the main effect of conversation condition $\left(\mathrm{F}(3,57)=.627, \mathrm{p}=.601, \eta_{\mathrm{p}}^{2}=.012\right)$ and the interaction between condition and age was not significant $\left(F(3,57)=.040, p=.842, \eta^{2} p=.001\right)$, suggesting that secondary glance frequency was unaffected by conversation condition for either age group. 


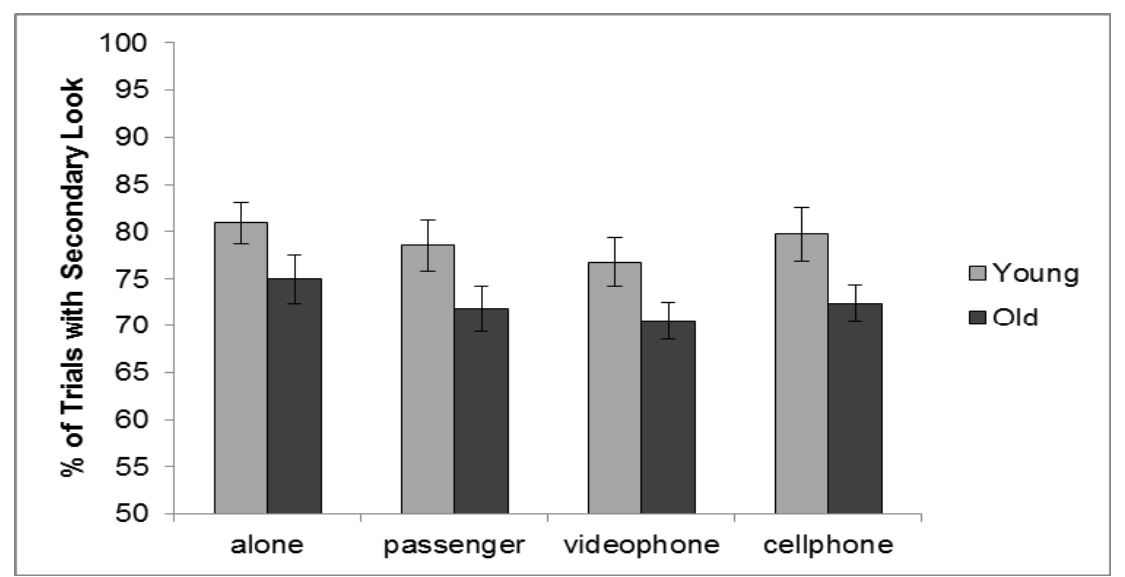

Figure 5. Percent of trials with a secondary look. Error bars represent within-subjects standard errors (Franz \& Loftus, 2012)

\section{DISCUSSION}

The goal of this study was to examine whether videophone conversations could enhance partner situational awareness and mitigate driver distraction during intersection driving. Our results replicate and extend those of Gaspar et al. (in press) by showing that the benefits of passenger conversations can be replicated by providing videophone information to a remote partner. Furthermore, the present study extends this finding by showing that videophones enhance situational awareness even when partners can see only a subset of the critical information in the driving scene. That is, videophone partners could not see oncoming traffic, yet still modulated their conversations relative to the cell phone condition. This suggests that providing information that the driver is approaching an intersection may be sufficient to boost situational awareness for remote conversation partners and may mitigate distraction effects.

The second question addressed by the present study was whether older drivers could also benefit from videophone conversations relative to cell phone conversations. Younger and older drivers showed an equivalent benefits for situational awareness and decision making time relative to the cell phone condition. Furthermore, in no case did older drivers show greater costs from passenger or videophone conversations than did younger drivers. These data are supported by a study by Kramer and colleagues (2007), which showed that despite baseline differences in simple reaction time, older drivers could utilize a side collision warning system just as well as younger drivers. From a theoretical perspective, it is likely that older adults were able to utilize their extensive driving experience, both as drivers and passengers, to overcome baseline physical and cognitive deficits (see Kramer \& Morrow, in press).

One critical point worth noting here is that conversation partners, whether as a passenger or videophone partner, must be actively attending the driving scene and must be able to modulate their conversation to yield a benefit relative to cell phones. For instance, recent studies suggest that distracting passengers (talking about something other than the driving scene) are similarly detrimental as remote cell phone partners (Strayer et al., 2013). This suggests that in order for videophone conversations to be effective in reducing driver distraction, conversation partners must remain free of distraction and be engaged in the driving task. Whether remote videophone partners are willing to remain attentive and undistracted is an important unresolved question. 
Furthermore, more research is needed to investigate potential impact of real-world implementation issues, such as lag in video transmission or ambient noise, on videophone interactions.

\section{ACKNOWLEDGMENTS}

The authors would like to acknowledge Chun Kim and Anya Knecht for their assistance with data collection, Nathan Ward for feedback and example images, and Daniel Simons for feedback. This work was supported by an Office of Naval Research grant to the last author.

\section{REFERENCES}

Drews, F. A., Pasupathi, M., \& Strayer, D. L. (2008). Passenger and cell phone conversations in simulated driving. Journal of Experimental Psychology: Applied, 14(4), 392.

Gaspar, J. G., Street, W. N., Windsor, M. B., Carbonari, R., Kaczmarski, H., Kramer, A. F., \& Mathewson, K. E. (In Press). Providing Views of the Driving Scene to Drivers' Conversation Partners Mitigates Cell-Phone-Related Distraction. Psychological Science.

Kramer, A. F., Cassavaugh, N., Horrey, W. J., Becic, E., \& Mayhugh, J. L. (2007). Influence of age and proximity warning devices on collision avoidance in simulated driving. Human Factors, 49(5), 935-949.

Kramer, A.F. \& Morrow, D. (in press). Cognitive training and expertise. In D. Park \& N. Schwartz (Eds.), Cognitive Aging: A Primer. Philadelphia, PA: Psychology Press.

Ma, R., \& Kaber, D. B. (2005). Situation awareness and workload in driving while using adaptive cruise control and a cell phone. International Journal of Industrial Ergonomics, 35(10), 939-953.

McCarley, J. S., Vais, M. J., Pringle, H., Kramer, A. F., Irwin, D. E., \& Strayer, D. L. (2004). Conversation disrupts change detection in complex traffic scenes. Human Factors, 46(3), 424-436.

Romoser, M. R., \& Fisher, D. L. (2009). The effect of active versus passive training strategies on improving older drivers' scanning in intersections. Human Factors, 51(5), 652-668.

Strayer, D., Cooper, J., Turrill, J., Coleman, J., Medeiros-Ward, N., \& Biondi, F. (2013). Measuring cognitive distraction in the automobile. AAA Foundation for Traffic Safety.

Strayer, D. L., Drews, F. A., \& Johnston, W. A. (2003). Cell phone-induced failures of visual attention during simulated driving. Journal of experimental psychology: Applied, 9(1), 23.

Strayer, D. L., \& Drews, F. A. (2004). Profiles in driver distraction: Effects of cell phone conversations on younger and older drivers. Human Factors, 46(4), 640-649.

Verhaeghen, P., Steitz, D. W., Sliwinski, M. J., \& Cerella, J. (2003). Aging and dual-task performance: a meta-analysis. Psychology and Aging, 18(3), 443. 